\title{
Research Article \\ Effect of Hydrocolloids and Emulsifiers on Baking Quality of Composite Cassava-Maize-Wheat Breads
}

\author{
Maria Eduardo, ${ }^{1,2}$ Ulf Svanberg, ${ }^{2}$ and Lilia Ahrnée ${ }^{2,3}$ \\ ${ }^{1}$ Departamento de Engenharia Química, Faculdade de Engenharia, Universidade Eduardo Mondlane, Maputo, Mozambique \\ ${ }^{2}$ Department of Chemical and Biological Engineering/Food Science, Chalmers University of Technology, Gothenburg, Sweden \\ ${ }^{3}$ The Swedish Institute for Food and Biotechnology (SIK), Gothenburg, Sweden \\ Correspondence should be addressed to Lilia Ahrné; lilia.ahrne@sik.se
}

Received 28 May 2014; Accepted 1 September 2014; Published 14 September 2014

Academic Editor: Philip Cox

Copyright (C) 2014 Maria Eduardo et al. This is an open access article distributed under the Creative Commons Attribution License, which permits unrestricted use, distribution, and reproduction in any medium, provided the original work is properly cited.

\begin{abstract}
Cassava is widely available worldwide but bread quality is impaired when cassava is used in the bread formulation. To overcome this problem, different improvers were tested in the preparation of composite cassava-maize-wheat (CMW) breads. Emulsifiers, diacetyl tartic acid ester of monoglycerides (DATEM), sodium stearoyl-2-lactylate (SSL), and lecithin (LC); and hydrocolloids, carboxymethylcellulose (CMC) and high-methylated pectin (HM pectin) were added during dough preparation of the composite flours (cassava-maize-wheat, $40: 10: 50$ ). Each emulsifier was tested in combination with the hydrocolloids at levels of $0.1,0.3$, and $0.5 \%$ while hydrocolloids were used at a level of $3 \%$. Bread quality attributes such as specific loaf volume, crust colour, crumb moisture, and firmness were measured. The specific volume of the fresh breads significantly improved with the addition of hydrocolloids (7.5 and 13\%) and in combination with emulsifiers (from 7.9 to $27 \%$ ) compared with bread produced without improvers. A significant improvement of brownness index and firmness of the composite flours breads was achieved with the addition of hydrocolloids and emulsifiers. The results show that emulsifiers and hydrocolloids can significantly improve the baking quality of CMW breads and thereby enhance the potential for using locally produced flours in bread baking.
\end{abstract}

\section{Introduction}

Use of composite flour in bread making has gained interest, especially in countries where wheat is not grown. According to FAO, 252 million tonnes of cassava was produced worldwide in 2011 [1]. This major food commodity has recently been promoted to be included in composite flour for bread making [2]. However, cassava contains no gluten, and partial substitution of wheat flour therefore impairs the quality of the bread. This effect has been attributed to reduced flour strength and gas retention capacity due to the lack of gluten proteins, thereby reducing bread volume and the sensory appeal of most baked composite bread [3]. To counteract these technological problems, several improvers have been used to mimic gluten properties.

Hydrocolloids are widely used to improve bread quality in wheat bread formulations $[4,5]$ and in gluten-free bread formulations in order to replace the viscoelastic and gas-binding properties of gluten [6-9]. Hydrocolloids also interact with the swelling, the gelatinization, and gelling properties of the dough and the retrogradation of the starch [10]. The type and dosage of hydrocolloids have significant effects on functional performance of the dough and subsequent bread quality. Xanthan gum has been reported to improve dough handling properties, loaf specific volume, and crumb softness when incorporated into composite cassava-wheat bread formulations [3]. Similar results were found by Yaseen et al. [11], who studied the use of gum arabic or pectin for the quality of corn-wheat pan bread. Correa et al. [12] showed that wheat bread with added high-methoxylated pectin (HM pectin) had a higher specific bread volume than bread with lowmethoxylated pectin. The explanation may be the ability of HM pectin to establish hydrophobic interactions with gluten proteins through their methoxyl groups [13]. According to Collar et al. [5], some hydrocolloids will preferentially bind to gluten, for example, carboxymethylcellulose (CMC), or to the 
starch granules, for example, hydroxypropylmethylcellulose (HPMC). This interaction was associated with a significant displacement of endogenous gluten-bounded lipids to the starchy fraction (CMC) and with a significant decrease in lipids bound to the outside part of the starch granules (HPMC).

Emulsifiers are substances possessing both hydrophobic and hydrophilic properties, and various types are widely used in commercial bread formulas [14-16]. As emulsifiers include compounds with completely different chemical structures, they are therefore expected to have different effects on the dough and bread properties [17, 18]. Emulsifiers can function as dough strengtheners that mainly interact with gluten proteins and as crumb softeners or antifirming agents that can complex gelatinized starch $[14,19,20]$. The dough improving effect of emulsifiers seems to be related to their effect in reducing the repulsing charges between gluten proteins and thereby causing them to aggregate. This effect appears to be of particular importance in composite flours, as the wheat gluten has been diluted. Emulsifiers also contribute to retarding starch retrogradation by inhibiting the migration of water through interaction with starch molecules $[4,21,22]$ and increasing gas cell stabilization in the dough by forming liquid lamellar films surrounding the gas cells $[23,24]$. Sodium stearoyl-2-lactylate (SSL) and diacetyl tartaric acid esters of monodiglycerides (DATEM) are common anionic emulsifiers that have been shown to improve bread crumb and crust texture, and softness $[4,25]$ and to increase loaf volume $[26,27]$. Due to their high hydrophilic/lipophilic balance, these improvers may promote aggregation of gluten proteins and form hydrogen bonds with glutamine and complex with starch granules [28] and thereby increase proteinstarch interactions $[29,30]$. These interactions generate a strong protein network and the development of a glutenstarch-lipid complex that as a result will produce bread with a better texture and increased volume [31,32]. However, Gómez et al. [33] observed different effects on the gluten structure by SSL and DATEM. SSL with a higher hydrophilic/lipophilic balance (HLB) value will allow interaction with gluten proteins through ionic bonds while DATEM with its lower HLB mainly interacts with hydrophobic domains of gluten proteins [34]. Furthermore, DATEM was shown to have interactive effects on dough strength with HM pectin [35]. Ravi et al. [36] concluded that DATEM had greater effects on weak wheat flours than on stronger flours. Lecithin (LC) has been proven to increase specific volume in wheat bread [21] and to promote softer bread crumb compared with DATEM [26].

In gluten-free breads, a higher specific volume was obtained with SSL, DATEM, and LC that was related to the strength of the dough [37]. Indrani and Rao [38] reported the same trend for wheat bread.

Although the improving effects of emulsifiers and hydrocolloids in baking have been studied, there is scarce information about the combined effects of hydrocolloids and emulsifiers on the quality of composite breads containing cassava flours. The objective of this investigation was to improve the baking quality of composite bread in a study of the effects of an addition of two hydrocolloids (CMC and HM pectin)
TABLE 1: Levels and types of emulsifiers and hydrocolloids added to composite cassava-maize-wheat (CMW) bread formulations.

\begin{tabular}{lccc}
\hline $\begin{array}{l}\text { Experiment } \\
\text { number }\end{array}$ & Emulsifier & $\begin{array}{c}\text { Level of } \\
\text { emulsifier } \\
\text { w/w })\end{array}$ & $\begin{array}{c}\text { Hydrocolloid } \\
(3 \% \mathrm{w} / \mathrm{w})\end{array}$ \\
\hline 1 & DATEM & 0.1 & CMC \\
2 & DATEM & 0.1 & HM pectin \\
3 & SSL & 0.1 & CMC \\
4 & SSL & 0.1 & HM pectin \\
5 & LC & 0.1 & CMC \\
6 & LC & 0.1 & HM pectin \\
7 & DATEM & 0.3 & CMC \\
8 & DATEM & 0.3 & HM pectin \\
9 & SSL & 0.3 & CMC \\
10 & SSL & 0.3 & HM pectin \\
11 & LC & 0.3 & CMC \\
12 & LC & 0.3 & HM pectin \\
13 & DATEM & 0.5 & CMC \\
14 & DATEM & 0.5 & HM pectin \\
15 & SSL & 0.5 & CMC \\
16 & SSL & 0.5 & HM pectin \\
17 & LC & 0.5 & CMC \\
18 & LC & 0.5 & HM pectin \\
\hline & & &
\end{tabular}

combined with different types of emulsifiers (DATEM, SSL, and LC) on specific volume, texture, colour, and moisture content of composite cassava-maize-wheat (CMW) bread.

\section{Materials and Methods}

2.1. Basic Ingredients and Improvers. Commercial wheat flour (Lilla Harrie Valskvarn AB, Göteborg, Sweden), yellow maize flour (AB Risenta, Sweden), dried active yeast (Saccharomyces cerevisiae), sodium chloride, sucrose, vegetable oil from soybeans, and ascorbic acid (GR, E. Merck) were used. Hydrocolloids were high-methylated pectin, HM pectin (GENU pectin type BIG, CP Kelco, Denmark), and carboxymethylcellulose, CMC (CEKOL 50000 W, CP Kelco, Denmark). Emulsifiers were diacetyl tartiric acid ester of monoglycerides, DATEM (MULTEC HP 20, Puratos, Belgium), sodium stearoyl lactylate, SSL (MULTEC 3000, Puratos, Belgium), and soy lecithin, LC (Sternchemie, Germany). All ingredients were purchased from commercial sources or directly from the suppliers. Fresh roots of cassava were obtained from local producers in Mozambique and then processed into flour of roasted cassava [2].

\subsection{Methods}

2.2.1. Experimental Plan Design. A full factorial experimental design [39] without replicates was set up and 18 composite bread productions $\left(3^{2} * 2=18\right.$ sets without centre points) were carried out in random order (Table 1). The main experiment consisted of five factors, namely, the type of 
TABLE 2: Specific loaf volume, moisture content, firmness, and brownness index value of composite cassava-maize-wheat (CMW) breads without hydrocolloids or emulsifiers.

\begin{tabular}{lcccc}
\hline Composite bread & Specific volume $\left(\mathrm{cm}^{3} / \mathrm{g}\right)$ & Moisture content $(\%)$ & Firmness $(\mathrm{N})$ & Brownness index \\
\hline CMW without hydrocolloids or emulsifiers & $1.94 \pm 0.06$ & $47.2 \pm 0.5$ & $7.14 \pm 0.3$ & $57.3 \pm 1.9$ \\
\hline
\end{tabular}

hydrocolloids (CMC and HM pectin) and type of emulsifiers (DATEM, SSL, and LC). Hydrocolloids were used at the same level of $3 \%$, while the emulsifiers were added at three levels $(0.1 \%, 0.3 \%$, and $0.5 \%)$. The samples were analyzed for specific volume, moisture content, crumb firmness, and crust colour.

2.2.2. Bread Processing. A bread recipe, based on flour weight, consisting of $500 \mathrm{~g}$ of flour (roasted cassava $40 \%$, maize $10 \%$, and wheat $50 \%$ ), $1.6 \%$ dry yeast, $1.5 \%$ salt, $3 \%$ vegetable oil from soybeans, $0.1 \%$ ascorbic acid, and $88.3 \%$ water, was used in this study. The bread processing followed a planned design presented in Table 1. The baking procedure and conditions were the same as in the previous study [2] and were as follows. The ingredients were mixed for $10 \mathrm{~min}$ in a mixer (Kitchen Aid, KSM9, Michigan, USA), allowed to rest at room temperature for $45 \mathrm{~min}$, divided into 20 loaves $(50 \mathrm{~g}$ each), hand molded, and placed into bread pans. Dough was proofed at $30^{\circ} \mathrm{C}$ and $80 \%$ relative humidity for 45 minutes. The loaves were baked at $220^{\circ} \mathrm{C}$ for $7 \mathrm{~min}$ in a convection oven (Dahlen S400, Sveba Dahlen AB, Sweden). After baking, the loaves were removed from the pans and allowed to rest for cooling for $60 \mathrm{~min}$ at ambient conditions $\left(25^{\circ} \mathrm{C}, 50 \%\right)$ before weighing. A composite cassava-maize-wheat (CMW) bread sample with no improvers was used as a control. Cooled bread samples were packaged in polypropylene bags to prevent moisture loss and were used for further analysis.

\subsection{Technological Evaluation of the Bread}

2.3.1. Specific Loaf Volume Measurement. Loaf volume was determined using the rapeseed displacement method, but using alfalfa seeds instead of rapeseeds. Each loaf $(n=6)$ was weighed and the volume was measured $60 \mathrm{~min}$ after being taken from the oven. The specific loaf volume was reported as $\mathrm{cm}^{3} / \mathrm{g}$ of the loaf.

2.3.2. Crust Colour. The colour was measured $180 \mathrm{~min}$ after baking in four loaves. Crust colour was quantified with the Digital Colour Imaging System (DigiEye) (Cromocol Scandinavia $\mathrm{AB}$, Borås, Sweden). The controlled illumination cabinet on the DigiEye equipment was utilized to capture high resolution images of the fresh bread surface. The DigiEye 2.53b software (Cromocol Scandinavia $\mathrm{AB}$, Borås, Sweden) allows for storage of specific colour standards with a given $L^{*}$ (lightness), $a^{*}$ (redness-greenness), and $b^{*}$ (yellownessblueness) values according to the CIELAB definition. The results were reported as brownness index (BI), calculated according to Maskan [40]:

$$
\mathrm{BI}=\frac{[100(x-0.31)]}{0.17}
$$

where

$$
x=\frac{a+1.75 L}{5.645 L+a-3.01 b} .
$$

2.3.3. Crumb Firmness. The crumb firmness was measured $6 \mathrm{~h}$ after baking using an Instron Universal Testing Machine (UTM, model 5542). The AACC standard method 74-09 was used. The measurements were carried out on $25 \mathrm{~mm}$ thick slices taken from the centre part of the loaf of bread. Samples were compressed to approximately $10 \mathrm{~mm}(40 \%$ of the thickness of the slice) at a test speed of $1.7 \mathrm{~mm} / \mathrm{s}$. The measurements were carried out on four loaves from each batch, and the compression force (in Newton) at the end of the compression was defined as firmness.

2.3.4. Moisture Content. The moisture content of fresh bread samples $(n=3)$ was determined by drying overnight in a vacuum oven at $70^{\circ} \mathrm{C}[41]$.

2.3.5. Crumb Grain Structure Analysis. The grain structure of the crumb was analyzed using pictures of composite bread crumbs taken with the Digital Colour Imaging System (DigiEye) (Cromocol Scandinavia $\mathrm{AB}$, Borås, Sweden) and Matlab software [42]. Images were stored in a TIF format of $4288 * 2848$ pixels, and a region with approximately 900 * 900 pixels was selected. The parameter measured was the mean cell area, expressed in $\mathrm{mm}^{2}$. This is the average of all cells' area:

$$
\text { Mean cell area }(\mathrm{MCA})=\frac{\text { Total area of cells }}{\text { Total number of cells }} \text {. }
$$

This characteristic gives an idea of the size of the cells of the bread crumb.

2.4. Statistical Analysis. All experiments were performed in a completely randomized design. A statistical difference in bread properties was determined by one-way analysis of variance (ANOVA) and Tukey's HSD post hoc multiple range test $(P<0.05)$.

\section{Results and Discussion}

Tables 2 and 3 show the results for specific loaf volume, moisture content, firmness, and brownness index value of the composite cassava-maize-wheat (CMW) bread loaves prepared without emulsifiers and hydrocolloids and prepared with the combinations of CMC or HM pectin as hydrocolloids and DATEM, SSL, or LC as emulsifiers.

There were significant $(P<0.05)$ differences in specific volume, firmness, and brownness index values between CMW control breads without improvers and bread samples 
TABLE 3: Effect of type and concentration of hydrocolloids ${ }^{1}$ and emulsifiers ${ }^{2}$ on specific loaf volume, moisture content, firmness, and brownness index value in composite cassava-maize-wheat (CMW) breads.

\begin{tabular}{|c|c|c|c|c|c|c|c|c|c|}
\hline \multirow{2}{*}{ Composite bread } & \multirow{2}{*}{ Level of emulsifier (\%) } & \multicolumn{2}{|c|}{ Specific volume $\left(\mathrm{cm}^{3} / \mathrm{g}\right)$} & \multicolumn{2}{|c|}{ Moisture content (\%) } & \multicolumn{2}{|c|}{ Firmness $(\mathrm{N})$} & \multicolumn{2}{|c|}{ Brownness index } \\
\hline & & $\mathrm{CMC}$ & HM-pectin & $\mathrm{CMC}$ & HM-pectin & $\mathrm{CMC}$ & HM-pectin & $\mathrm{CMC}$ & HM-pectin \\
\hline No emulsifier & 0 & $2.14^{\mathrm{a}}$ & $2.07^{\mathrm{bc}}$ & $47.9 \pm 0.1$ & $48.0 \pm 0.1$ & $4.71^{\mathrm{de}}$ & $6.15^{\mathrm{e}}$ & $80.0^{\mathrm{ab}}$ & $66.2^{\mathrm{a}}$ \\
\hline \multirow{3}{*}{ +DATEM } & 0.1 & $2.23^{\mathrm{ab}}$ & $2.08^{\mathrm{bcd}}$ & & & $4.97^{\mathrm{ef}}$ & $5.56^{\mathrm{d}}$ & $88.8^{\mathrm{d}}$ & $82.3^{\mathrm{de}}$ \\
\hline & 0.3 & $2.46^{\mathrm{e}}$ & $2.21^{\mathrm{de}}$ & $47.5 \pm 0.4$ & $48.6 \pm 1.7$ & $4.39^{\mathrm{bc}}$ & $4.99^{\mathrm{b}}$ & $87.9^{\mathrm{cd}}$ & $97.9^{\mathrm{g}}$ \\
\hline & 0.5 & $2.38^{\text {cde }}$ & $2.19^{\mathrm{de}}$ & & & $4.59^{\mathrm{cd}}$ & $5.16^{\mathrm{bc}}$ & $95.2^{\mathrm{e}}$ & $93.2^{\mathrm{f}}$ \\
\hline \multirow{3}{*}{+ SSL } & 0.1 & $2.40^{\mathrm{de}}$ & $2.06^{\mathrm{ab}}$ & & & $3.85^{\mathrm{a}}$ & $5.41^{\mathrm{cd}}$ & $84.1^{\mathrm{bc}}$ & $84.7^{\mathrm{e}}$ \\
\hline & 0.3 & $2.31^{\mathrm{bcd}}$ & $2.16^{\text {bcde }}$ & $47.3 \pm 0.3$ & $47.5 \pm 0.5$ & $4.84^{\mathrm{de}}$ & $4.98^{\mathrm{b}}$ & $84.8^{\mathrm{cd}}$ & $76.9^{\mathrm{bc}}$ \\
\hline & 0.5 & $2.29^{\mathrm{bc}}$ & $2.31^{\mathrm{f}}$ & & & $5.17^{\mathrm{f}}$ & $5.00^{\mathrm{b}}$ & $76.7^{\mathrm{a}}$ & $85.3^{\mathrm{e}}$ \\
\hline \multirow{3}{*}{$+\mathrm{LC}$} & 0.1 & $2.22^{\mathrm{ab}}$ & $2.18^{\text {cde }}$ & & & $5.26^{\mathrm{f}}$ & $5.33^{\text {bcd }}$ & $87.0^{\mathrm{cd}}$ & $78.4^{\mathrm{cd}}$ \\
\hline & 0.3 & $2.33^{\mathrm{cd}}$ & $2.26^{\mathrm{de}}$ & $47.4 \pm 0.3$ & $47.6 \pm 0.3$ & $4.28^{\mathrm{b}}$ & $4.61^{\mathrm{a}}$ & $86.1^{\mathrm{cd}}$ & $79.9^{\mathrm{cd}}$ \\
\hline & 0.5 & $2.38^{\text {cde }}$ & $2.16^{\text {bcde }}$ & & & $4.53^{\mathrm{bcd}}$ & $5.16^{\mathrm{bc}}$ & $85.1^{\mathrm{cd}}$ & $73.8^{\mathrm{b}}$ \\
\hline
\end{tabular}

${ }^{1}$ CMC: cellulose gum, HM pectin: high methoxyl pectin at $3 \%(\mathrm{w} / \mathrm{w})$ level, ${ }^{2}$ DATEM: diacetyl tartaric acid ester of mono- and diglycerides, SSL: sodium stearoyl-2-lactylate, and LC: soy lecithin (\% in w/w).

a,b,c,d,e,f,g Different letters in the same column represent values that are significantly different $(P<0.05)$.

with hydrocolloids and emulsifiers. The effect of these baking improvers on quality parameters was dependent on the type of hydrocolloid and level of emulsifier. An increase was observed for specific volume and crust colour values while crumb firmness showed a decrease. Crumb moisture content did not change as an effect of adding emulsifiers and was in the range from 47.3 to $48.6 \%(\mathrm{w} / \mathrm{w})$.

3.1. Specific Volume of the Loaves. The specific volume of the breads increased $(P<0.05)$ as an effect of added hydrocolloids at a level of $3 \%$, from $1.94 \mathrm{~cm}^{3} / \mathrm{g}$ in the CMW control bread to $2.14 \mathrm{~cm}^{3} / \mathrm{g}$ with CMC and to $2.07 \mathrm{~cm}^{3} / \mathrm{g}$ with HM pectin; see Tables 2 and 3. Similar effects on specific bread volume have been reported with additions of xanthan gum, HPMC, and $\kappa$-carrageenan to wheat bread [8], of HPMC to gluten-free maize-teff bread [43], and of pectin and CMC to gluten-free formulations [44]. These findings might be a result of the formation of a gel network during oven heating that strengthens the expanding cells of the dough and, as a result, improves gas retention and bread volume [45]. Roasted cassava flour with pregelatinized starch granules and partly leached amylose may also contribute to build up a network with the hydrocolloids during the dough phase [46]. A network of this kind with pregelatinized cassava could improve gas-holding properties in the dough phase [47] and has been shown to result in a higher specific volume of sorghum-cassava bread $[48,49]$.

Compared with control bread, the specific volume increased further $(P<0.05)$ with the addition of emulsifiers, depending on the type and concentration; see Figure 1. For breads with $\mathrm{CMC}$, the specific volume increased between 23 and $27 \%$ to $2.46 \mathrm{~cm}^{3} / \mathrm{g}$ with DATEM $(0.3 \%), 2.40 \mathrm{~cm}^{3} / \mathrm{g}$ with SSL $(0.1 \%)$, and $2.38 \mathrm{~cm}^{3} / \mathrm{g}$ with LC $(0.5 \%)$. In breads with HM pectin, the increase in the specific volume was comparatively lower, between 14 and 19\%, with the highest value, $2.31 \mathrm{~cm}^{3} / \mathrm{g}$, in bread with SSL at a level of $0.5 \%$. The

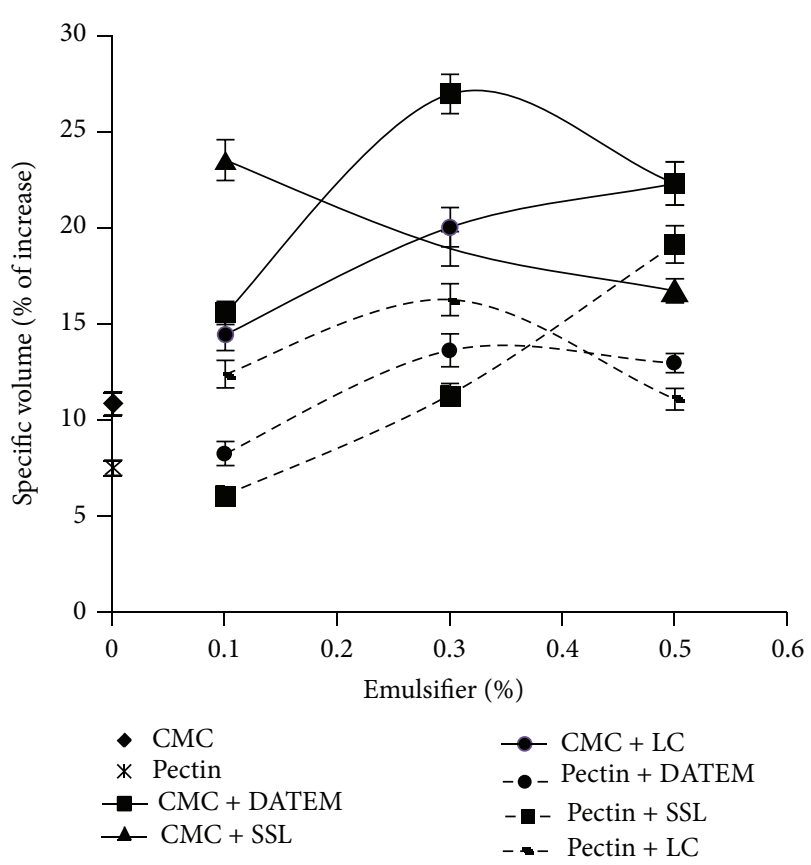

FIGURE 1: Specific volume increase (\%) due to hydrocolloids CMC and pectin at a level of 3\% and emulsifier types (DATEM, SSL, and LC) at different levels of addition. The error bars represent the standard deviation.

larger specific volume of CMW bread loaves prepared with CMC compared with HM pectin may be explained by a higher ability of CMC to interact with the gluten proteins, resulting in a more stable dough and better volume $[5,12]$.

Rogers and Hoseney [50] reported that additions of DATEM and SSL improved the loaf volume of wheat bread. Similar results were reported by Nunes et al. [37] when LC and DATEM $(0.5 \%)$ were added in the formulation of 


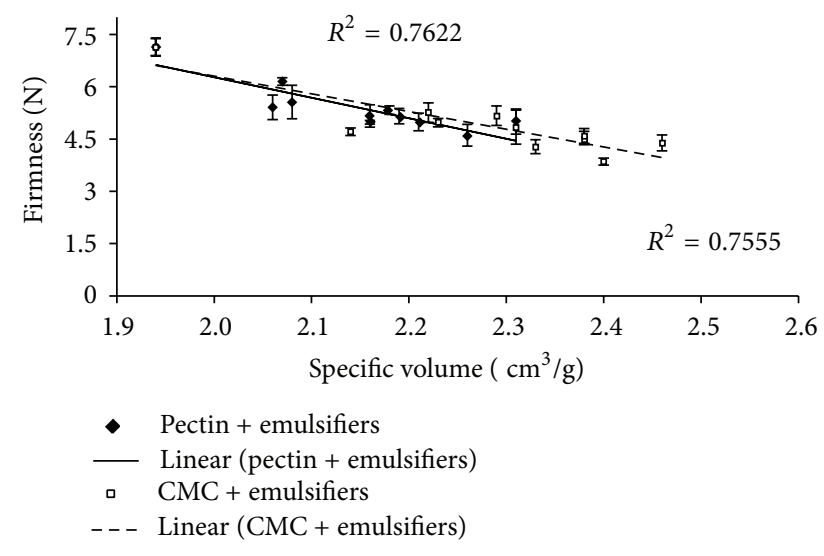

FIGURE 2: Correlation between firmness of the composite bread crumb and the specific volume. The error bars represent the standard deviation.

gluten-free bread formulations. The positive effect on bread volume of emulsifiers is caused by their dough strengthening properties by forming liquid films with a lamellar structure in the interphase between the gluten strands and the starch [14]. Krog [51] reported that SSL and DATEM were the most effective in creating this lamellar structure.

Our results can be explained on the basis of the structural properties of the emulsifiers. The amphiphilic nature of emulsifiers may contribute to the strength of the gluten network; in general, anionic emulsifiers, such as DATEM and SSL, will increase the strength of the dough by interacting with hydrophobic regions of the gluten proteins and forming hydrogen bonds with the amino groups of glutamine $[14,19$, $26,52]$. The improved dough strength will allow better carbon dioxide retention during oven spring and, as a result, will give bread with improved loaf volume $[26,53]$. However, an addition of lecithin has been shown to reduce the stability of wheat flour dough [19].

3.2. Crumb Moisture. The moisture content in the crumbs of breads increased slightly with added hydrocolloids (47.9$48.0 \%)$ in comparison with the CMW control bread (47.2\%). These results are in agreement with the work of Bárcenas and Rosell [54], who reported that the addition of HPMC increased the crumb moisture content of white bread. In general, crumb moisture was unaffected by the addition of an emulsifier.

3.3. Crumb Firmness. Data on texture of breads with different emulsifiers are presented in Tables 2 and 3.

Hydrocolloids reduced the crumb firmness compared to the CMW bread $(7.1 \pm 0.25 \mathrm{~N})$. The reduction in the crumb firmness with the addition of either CMC or HM pectin was about $34 \%$ and $14 \%$, respectively. According to Biliaderis et al. [55], hydrocolloids may decrease granular swelling of the starch and the amount of amylose leached from the granules and, as a result, hinder a building up of an amylose network and thereby result in a softer crumb. On the other hand, the roasted cassava flour used in the composite flour mixture is highly gelatinized with partially swelled starch granules and retrograded leached amylose [46]. The linear polysaccharide in CMC may interfere with the amylose of the gelatinized cassava starch granules breaking the gel network, which might explain the softening of the bread crumb [56]. The better effect of CMC compared with HM pectin is in line with a relatively higher volume of CMC bread, which might be explained by a better affinity of CMC to gluten than that of HM pectin [5].

Emulsifiers that can complex amylose are more efficient in reducing bread firmness than those that do not form complexes. The higher the complex-forming power of the emulsifier, the lower the initial bread crumb firmness [14, 57]. Monoacylglycerols are known as the most efficient crumb softeners, and both SSL and DATEM, with one stearic acid in the structure, might be expected to have a similar effect on bread firmness. In bread with CMC, the addition of emulsifiers had a lower effect on crumb firmness as compared with HM pectin bread. The highest reduction was observed for SSL at the level of $0.1 \%$ (18.3\%), followed by LC (9.1\%) and DATEM $(6.8 \%)$, both at the level of $0.3 \%(P<0.05)$.

In HM pectin bread, however, the addition of emulsifiers had stronger crumb softening effects, and the crumb firmness with LC was $4.71 \mathrm{~N}$, which was 35\% lower as compared with CMW bread. The reducing effect of DATEM and SSL on firmness has been reported for wheat breads by Ribotta et al. [27]. Gómez et al. [26] reported the same effect by lecithin. The positive effect of DATEM has been explained by its capacity to aggregate gluten proteins, which create a gluten network that can improve the entrapment of air and result in better bread volume and crumb texture.

Figure 2 shows similar correlations between firmness and specific volume of the composite breads with CMC $\left(R^{2}=\right.$ $0.762)$ and HM pectin $\left(R^{2}=0.755\right)$ and, as expected, these two properties are strongly correlated and do not significantly depend on the type of emulsifier. Higher values in the specific volume led to a softer bread crumb. However, the lower value of the correlation coefficient may indicate that the volume change is not the only factor causing reduction of bread firmness.

3.4. Crust Colour. The brownness index of bread samples with either CMC or HM pectin was increased by $40 \%$ and $16 \%$, respectively, compared with CMW bread (BI value of $53.3 \pm 1.9)$.

The literature gives conflicting results on crust colour as an effect of hydrocolloids. Lighter bread was obtained with xanthan gum in composite cassava-wheat bread [3]; darker bread was obtained in gluten-free formulations with xanthan gum [58], HPMC, and carrageenan [9]; lighter bread resulted with CMC [58] and xanthan gum [9]; and no effect on crust colour was observed with pectin, CMC, and xanthan [44].

With the addition of emulsifiers, the BI values significantly increased in all breads containing HM pectin. With DATEM, the BI values increased from 66 to between 82 and 98 , with the highest value at the $0.3 \%$ level. The BI values in loaves with SSL varied between 77 and 85 and in loaves with LC between 74 and 80 . However, there was no effect on the BI 


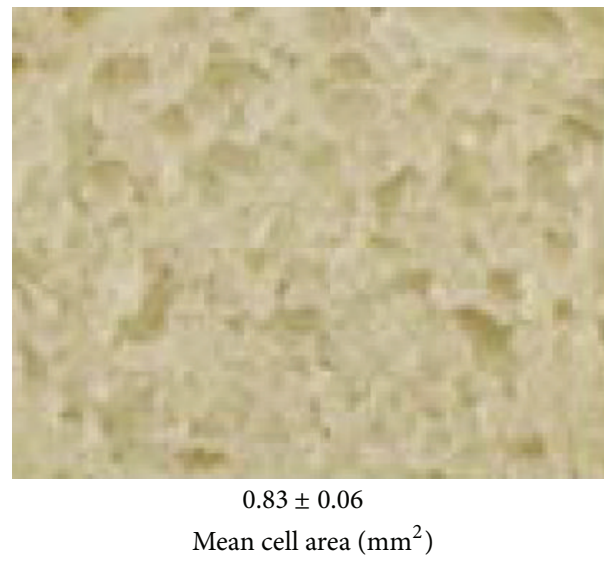

(a)

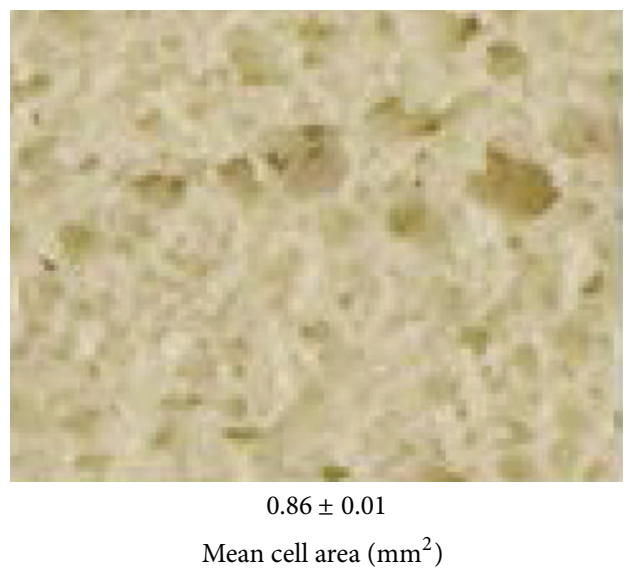

(b)

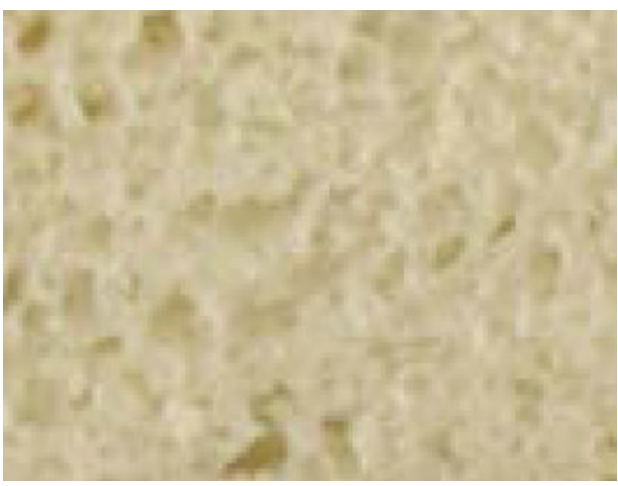

$1.12 \pm 0.10$

Mean cell area $\left(\mathrm{mm}^{2}\right)$

(c)

FIGURE 3: Crumb grain structure showing the mean cell area $\left(\mathrm{mm}^{2}\right)$ for composite cassava-maize-wheat bread (a) without improvers; (b) $+\mathrm{CMC}$; and (c) +HM pectin.

values with addition of SSL to the CMC bread (BI value of 80 ), while the BI values significantly increased with an addition of DATEM (up to 95) and an addition of LC (up to 87).

Thus, several composite breads with hydrocolloids and emulsifiers had BI values in the range from 82 to 86 , values that received a high score in a consumer acceptance test of CMW breads [59].

3.5. Crumb Grain Structure. The grain structure of the crumb in CMW breads as it is affected by the hydrocolloids and emulsifiers has been described by image analysis using the mean cell area $\left(\mathrm{mm}^{2}\right)$ (Table 4). Bread baked with HM pectin showed a higher mean cell area $\left(1.12 \pm 0.10 \mathrm{~mm}^{2}\right)$ compared with CMC $\left(0.86 \pm 0.01 \mathrm{~mm}^{2}\right)$ and composite cassava bread $\left(0.83 \pm 0.10 \mathrm{~mm}^{2}\right)$ without any improver, which means a more porous crumb structure (Figure 3 ). However, an addition of SSL to loaves containing pectin significantly reduced the mean cell area to between 0.76 and $0.83 \mathrm{~mm}^{2}$. On the other hand, in composite bread with CMC, the mean cell area was significantly increased by an addition of emulsifiers at $0.3 \%$
TABLE 4: Mean cell area of composite cassava-maize-wheat (CMW) bread as affected by the hydrocolloids (CMC and HM pectin) and emulsifier types (DATEM, SSL, and LC) at different levels of addition.

\begin{tabular}{lccc}
\hline $\begin{array}{l}\text { Composite } \\
\text { bread }\end{array}$ & $\begin{array}{l}\text { Level of } \\
\text { emulsifier (\%) }\end{array}$ & \multicolumn{2}{c}{ Mean cell area $\left(\mathrm{mm}^{2}\right)^{*}$} \\
\hline No emulsifier & 0 & $0.86 \pm 0.01$ & HM-pectin \\
\hline \multirow{2}{*}{+ DATEM } & 0.1 & $1.18 \pm 0.21$ & $1.23 \pm 0.10$ \\
& 0.3 & $1.39 \pm 0.25$ & $1.00 \pm 0.12$ \\
\hline \multirow{3}{*}{+ SSL } & 0.5 & $0.96 \pm 0.03$ & $1.08 \pm 0.02$ \\
\hline & 0.1 & $0.74 \pm 0.01$ & $0.81 \pm 0.15$ \\
& 0.3 & $0.94 \pm 0.03$ & $0.76 \pm 0.03$ \\
+ LC & 0.5 & $0.80 \pm 0.05$ & $0.83 \pm 0.00$ \\
\hline & 0.1 & $0.75 \pm 0.15$ & $1.17 \pm 0.01$ \\
& 0.3 & $1.54 \pm 0.07$ & $0.92 \pm 0.04$ \\
& 0.5 & $0.89 \pm 0.07$ & $0.88 \pm 0.12$ \\
\hline
\end{tabular}

${ }^{*}$ The values are represented by mean value $(n=2) \pm$ standard deviation. 
level. These results are in accordance with a higher specific volume that was observed for these breads (Table 3 ).

\section{Conclusions}

Addition of either CMC or HM pectin as baking improvers to composite cassava-maize-wheat (CMW) bread loaves improved bread quality parameters such as specific volume, crust colour, and crumb texture. In general, emulsifiers in combination with CMC had a more positive effect on bread specific volume compared with HM pectin, which can be explained by differences in interactions of CMC or pectin with emulsifiers and the gluten protein network created in the composite bread. The crumb grain structure was greatly affected by pectin or by a combination of CMC and emulsifiers (especially DATEM and LC).

Overall, the results of this study suggest that the quality of CMW breads can be significantly improved by an addition of hydrocolloids or mixtures of hydrocolloids and emulsifiers as baking improvers. These baking improvers enhance the potential of using locally produced flours, such as cassava and maize, in composite flour for bread making in South East Africa.

\section{Conflict of Interests}

The authors declare that there is no conflict of interests regarding the publication of this paper.

\section{Acknowledgment}

Financial support from the Swedish International Development Agency (SIDA) programme under the Project "Energy Science and Technology Research" is gratefully acknowledged.

\section{References}

[1] Food and Agriculture Organization of the United Nations, Save and Grow Cassava: A Guide to Sustainable Production Intensification, Food and Agriculture Organization of the United Nations, Rome, Italy, 2013.

[2] M. Eduardo, U. Svanberg, J. Oliveira, and L. Ahrné, "Effect of cassava flour characteristics on properties of cassava-wheatmaize composite bread types," International Journal of Food Science, vol. 2013, Article ID 305407, 10 pages, 2013.

[3] T. A. Shittu, R. A. Aminu, and E. O. Abulude, "Functional effects of xanthan gum on composite cassava-wheat dough and bread," Food Hydrocolloids, vol. 23, no. 8, pp. 2254-2260, 2009.

[4] C. Collar, E. Armero, and J. Martínez, "Lipid binding of formula bread doughs: relationships with dough and bread technological performance," Zeitschrift für Lebensmitteluntersuchung und -Forschung A, vol. 207, no. 2, pp. 110-121, 1998.

[5] C. Collar, P. Andreu, J. C. Martínez, and E. Armero, "Optimization of hydrocolloid addition to improve wheat bread dough functionality: a response surface methodology study," Food Hydrocolloids, vol. 13, no. 6, pp. 467-475, 1999.

[6] J. A. Delcour, S. Vanhamel, and R. C. Hoseney, "Physicochemical and functional properties of rye nonstarch polysaccharides.
II. Impact of a fraction containing water-soluble pentosans and proteins on gluten starch loaf volumes," Cereal Chemistry, vol. 68, pp. 72-76, 1991.

[7] A. Guarda, C. M. Rosell, C. Benedito, and M. J. Galotto, "Different hydrocolloids as bread improvers and antistaling agents," Food Hydrocolloids, vol. 18, no. 2, pp. 241-247, 2004.

[8] C. M. Rosell, J. A. Rojas, and C. Benedito de Barber, "Influence of hydrocolloids on dough rheology and bread quality," Food Hydrocolloids, vol. 15, no. 1, pp. 75-81, 2001.

[9] D. Sabanis and C. Tzia, "Effect of hydrocolloids on selected properties of gluten-free dough and bread," Food Science and Technology International, vol. 17, no. 4, pp. 279-291, 2011.

[10] E. K. Arendt and M. M. Moore, "Gluten-free cereal-based products," in Bakery Products Science and Technology, H. Corke, I. de Leyn, W. K. Nip, N. Cross, and Y. H. Hui, Eds., pp. 471-495, Blackwell Publishing, Ames, Iowa, USA, 2006.

[11] A. A. Yaseen, A. A. Shouk, and M. R. Ramadan, "Corn-wheat pan bread quality as affected by hydrocolloids," Journal of American Science, vol. 6, pp. 1-7, 2010.

[12] M. J. Correa, G. T. Pérez, and C. Ferrero, "Pectins as breadmaking additives: effect on dough rheology and bread quality," Food and Bioprocess Technology, vol. 5, no. 7, pp. 2889-2898, 2012.

[13] S. H. Christensen, "Pectins," in Food Hydrocolloids, M. Glicksman, Ed., vol. 3, pp. 205-230, CRC Press, Boca Raton, Fla, USA, 1982.

[14] L. Stampfli and B. Nersten, "Emulsifiers in bread making," Food Chemistry, vol. 52, no. 4, pp. 353-360, 1995.

[15] J. A. Gray and J. N. Bemiller, "Bread staling: Molecular basis and control," Comprehensive Reviews in Food Science and Food Safety, vol. 2, no. 1, pp. 1-21, 2003.

[16] H. Goesaert, K. Brijs, W. S. Veraverbeke, C. M. Courtin, K. Gebruers, and J. A. Delcour, "Wheat flour constituents: how they impact bread quality, and how to impact their functionality," Trends in Food Science and Technology, vol. 16, no. 1-3, pp. 12-30, 2005.

[17] C. E. Stauffer, "Emulsifiers and dough strengtheners," in Functional Additives for Bakery Foods, C. E. Stauffer, Ed., pp. 69-124, Van Nostrand Reinhold, New York, NY, USA, 1990.

[18] C. E. Stauffer, "Emulsifiers," in Food Emulsifiers, pp. 25-45, AACC International, St. Paul, Minn, USA, 1999.

[19] L. Stampfli, B. Nersten, and E. L. Molteberg, "Effects of emulsifiers on farinograph and extensograph measurements," Food Chemistry, vol. 57, no. 4, pp. 523-530, 1996.

[20] J. A. Delcour and R. C. Hoseney, Principles of Cereal Science and Technology, AACC, St. Paul, Minn, USA, 2010.

[21] P. Forssell, S. Shamekh, H. Harkonen, and K. Poutanen, "Effects of native and enzymatically hydrolysed soya and oat lecithins in starch phase transitions and bread staling," Journal of the Science of Food and Agriculture, vol. 76, pp. 31-38, 1998.

[22] C. E. Stauffer, "Emulsifiers as antistaling agents," Cereal Foods World, vol. 45, no. 3, pp. 106-110, 2000.

[23] Z. Gan, P. R. Ellis, and J. D. Schofield, "Gas cell stabilisation and gas retention in wheat bread dough," Journal of Cereal Science, vol. 21, no. 3, pp. 215-230, 1995.

[24] B. S. Sroan and F. MacRitchie, "Mechanism of gas cell stabilization in breadmaking, II: the secondary liquid lamellae," Journal of Cereal Science, vol. 49, no. 1, pp. 41-46, 2009.

[25] A.-C. Eliasson, "Differential scanning calorimetry studies on wheat starch-gluten mixtures. II. Effect of gluten and sodium stearoyl lactylate on starch crystallization during ageing of 
wheat starch gels," Journal of Cereal Science, vol. 1, no. 3, pp. 207213, 1983.

[26] M. Gómez, S. Del Real, C. M. Rosell, F. Ronda, C. A. Blanco, and P. A. Caballero., "Functionality of different emulsifiers on the performance of breadmaking and wheat bread quality," European Food Research and Technology, vol. 219, no. 2, pp. 145150, 2004.

[27] P. D. Ribotta, G. T. Pérez, A. E. León, and M. C. Añón, "Effect of emulsifier and guar gum on micro structural, rheological and baking performance of frozen bread dough," Food Hydrocolloids, vol. 18, no. 2, pp. 305-313, 2004.

[28] W. Hähnel, I. Jussofie, and F. Müller, "Investigations into the properties of emulsifiers in yeast-leavened dough by means of infrared spectroscopy-II. Experiments on the interaction of emulsifiers with starch and flour and in dough," Zeitschrift für Lebensmittel-Untersuchung und -Forschung, vol. 200, no. 4, pp. 244-246, 1995.

[29] N. M. Edwards, J. E. Dexter, and M. G. Scanlon, "Starch participation in durum dough linear viscoelastic properties," Cereal Chemistry, vol. 79, no. 6, pp. 850-856, 2002.

[30] K. E. Petrofsky and R. C. Hoseney, "Rheological properties of dough made with starch and gluten from several cereal sources," Cereal Chemistry, vol. 72, no. 1, pp. 53-58, 1995.

[31] E. Mettler and W. Seibel, "Effect of emulsifiers and hydrocolloids on whole wheat bread quality: a response surface methodology study," Cereal Chemistry, vol. 70, pp. 373-377, 1993.

[32] A. Aamodt, E. M. Magnus, and E. M. Færgestad, "Effect of flour quality, ascorbic acid, and DATEM on dough rheological parameters and hearth loaves characteristics," Journal of Food Science, vol. 68, no. 7, pp. 2201-2210, 2003.

[33] A. V. Gómez, E. G. Ferrer, M. C. Añón, and M. C. Puppo, "Changes in secondary structure of gluten proteins due to emulsifiers," Journal of Molecular Structure, vol. 1033, pp. 51-58, 2013.

[34] E. Armero and C. Collar, "Antistaling additive effects on fresh wheat bread quality," Food Science and Technology International, vol. 2, no. 5, pp. 323-333, 1996.

[35] C. Bollaín and C. Collar, "Dough viscoelastic response of hydrocolloid/enzyme/surfactant blends assessed by uni- and biaxial extension measurements," Food Hydrocolloids, vol. 18, no. 3, pp. 499-507, 2004.

[36] R. Ravi, R. Sai Manohar, and P. Haridas Rao, "Influence of additives on the rheological characteristics and baking quality of wheat flours," European Food Research and Technology, vol. 210, no. 3, pp. 202-208, 2000.

[37] M. H. B. Nunes, M. M. Moore, L. A. M. Ryan, and E. K. Arendt, "Impact of emulsifiers on the quality and rheological properties of gluten-free breads and batters," European Food Research and Technology, vol. 228, no. 4, pp. 633-642, 2009.

[38] D. Indrani and G. V. Rao, "Influence of surfactants on rheological characteristics of dough and quality of parotta," International Journal of Food Science and Technology, vol. 38, no. 1, pp. 47-54, 2003.

[39] L. Eriksson, E. Johansson, N. Kettaneh-Wold, C. Wikstr, and S. Wold, Design of Experiments: Principles and Applications, Umetrics, Sweden, 3rd edition, 2008.

[40] M. Maskan, "Kinetics of colour change of kiwifruits during hot air and microwave drying," Journal of Food Engineering, vol. 48, no. 2, pp. 169-175, 2001.

[41] AACC, Approved Methods of the American Association of Cereal Chemists, AACC, St. Paul, Minn, USA, 9th edition, 1995.
[42] K. Douard, "Description of bread crumb structure by digital image analysis," Report, SIK, Stockholm, Sweden, 2012.

[43] A.-S. Hager and E. K. Arendt, "Influence of hydroxypropylmethylcellulose (HPMC), xanthan gum and their combination on loaf specific volume, crumb hardness and crumb grain characteristics of gluten-free breads based on rice, maize, teff and buckwheat," Food Hydrocolloids, vol. 32, no. 1, pp. 195-203, 2013.

[44] A. Lazaridou, D. Duta, M. Papageorgiou, N. Belc, and C. G. Biliaderis, "Effects of hydrocolloids on dough rheology and bread quality parameters in gluten-free formulations," Journal of Food Engineering, vol. 79, no. 3, pp. 1033-1047, 2007.

[45] D. A. Bell, "Methylcellulose as a structure enhancer in bread baking," Cereal Foods World, vol. 35, pp. 1001-1006, 1990.

[46] L. D. Tivana, P. Dejmek, and B. Bergenståhl, "Characterization of the agglomeration of roasted shredded cassava (Manihot esculenta crantz) roots," Starch/Staerke, vol. 62, no. 12, pp. 637646, 2010.

[47] M. Satin, "Bread without wheat. Novel ways of making bread from cassava and sorghum could reduce the Third World's dependence on imported wheat for white bread," New Scientist, vol. 28, pp. 56-59, 1988.

[48] O. Olatunji, A. Osibanjo, E. Bamiro, O. Ojo, and P. Bureng, "Improvement in the quality of non-wheat composite bread," in Proceedings of the 5th Quadrennial Symposium on Sorghum and Millets, pp. 45-54, International Association for Cereal Science and Technology, Schwechart, Austria, 1992.

[49] L. F. Hugo, R. D. Waniska, and L. W. Rooney, "Production of bread from composite flours," in Harnessing Cereal Science and Technology for Sustainable Development, pp. 100-114, CSIRICCSA Symposium, Pretoria, South Africa, 1997.

[50] D. E. Rogers and R. C. Hoseney, "Breadmaking properties of DATEM," Baker's Digest, vol. 57, pp. 12-16, 1983.

[51] N. Krog, "Theoretical aspects of surfactants in relation to their use in breadmaking," Cereal Chemistry, vol. 58, pp. 158-164, 1981.

[52] M. H. Azizi and G. V. Rao, "Effect of surfactant gels on dough rheological characteristics and quality of bread," Critical Reviews in Food Science and Nutrition, vol. 44, no. 7-8, pp. 545552, 2004.

[53] W. R. Moore and R. C. Hoseney, "Influence of shortening and surfactants on retention of carbon dioxide in bread dough," Cereal Chemistry, vol. 63, no. 2, pp. 67-70, 1986.

[54] M. E. Bárcenas and C. M. Rosell, "Effect of HPMC addition on the microstructure, quality and aging of wheat bread," Food Hydrocolloids, vol. 19, no. 6, pp. 1037-1043, 2005.

[55] C. G. Biliaderis, I. Arvanitoyannis, M. S. Izydorczyk, and D. J. Prokopowich, "Effect of hydrocolloids on gelatinization and structure formation in concentrated waxy maize and wheat starch gels," Starch/Staerke, vol. 49, no. 7-8, pp. 278-283, 1997.

[56] W. Tongdeesoontorn, L. J. Mauer, S. Wongruong, P. Sriburi, and P. Rachtanapun, "Effect of carboxymethyl cellulose concentration on physical properties of biodegradable cassava starchbased films," Chemistry Central Journal, vol. 5, article 6, 2011.

[57] K. Sawa, S. Inoue, E. Lysenko, N. M. Edwards, and K. R. Preston, "Effects of purified monoglycerides on Canadian short process and sponge and dough mixing properties, bread quality and crumb firmness during storage," Food Chemistry, vol. 115, no. 3, pp. 884-890, 2009.

[58] L. S. Sciarini, P. D. Ribotta, A. E. León, and G. T. Pérez, "Effect of hydrocolloids on gluten-free batter properties and bread 
quality," International Journal of Food Science and Technology, vol. 45, no. 11, pp. 2306-2312, 2010.

[59] M. Eduardo, U. Svanberg, and L. Ahrné, “Consumer's acceptance of composite cassava-maize-wheat breads using baking improvers," African Journal of Food Science, vol. 8, pp. 390-401, 2014. 

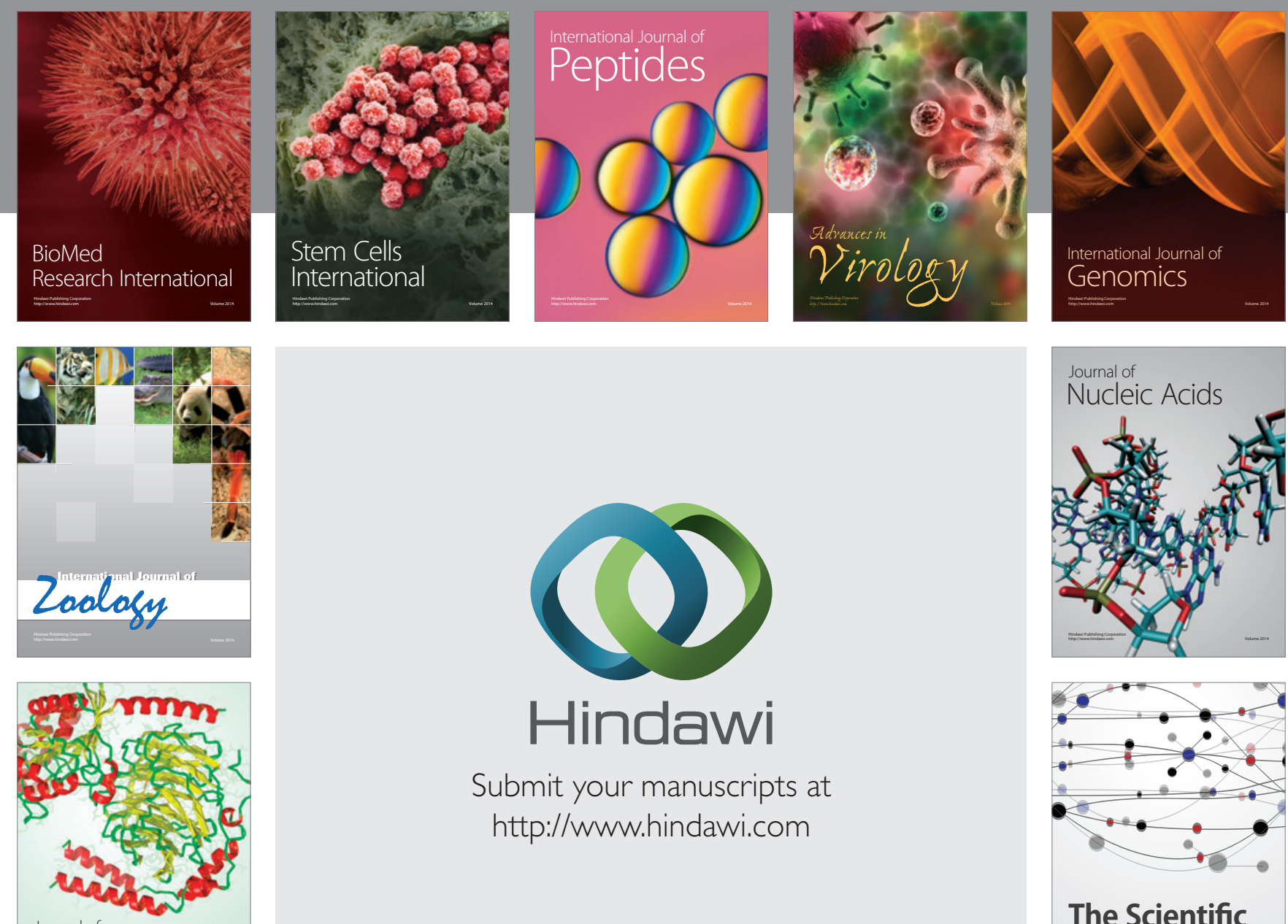

Submit your manuscripts at

http://www.hindawi.com

Journal of
Signal Transduction
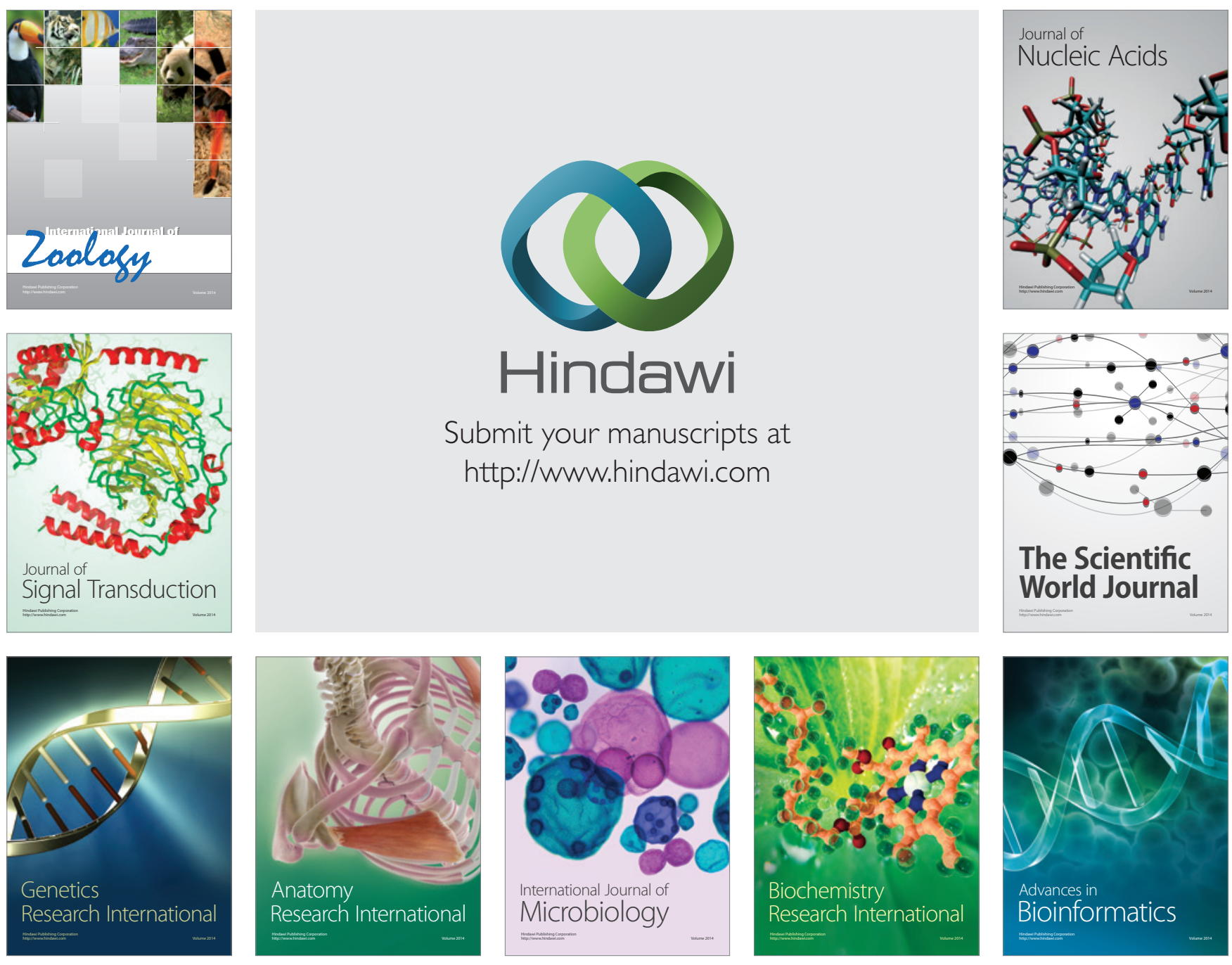

The Scientific World Journal
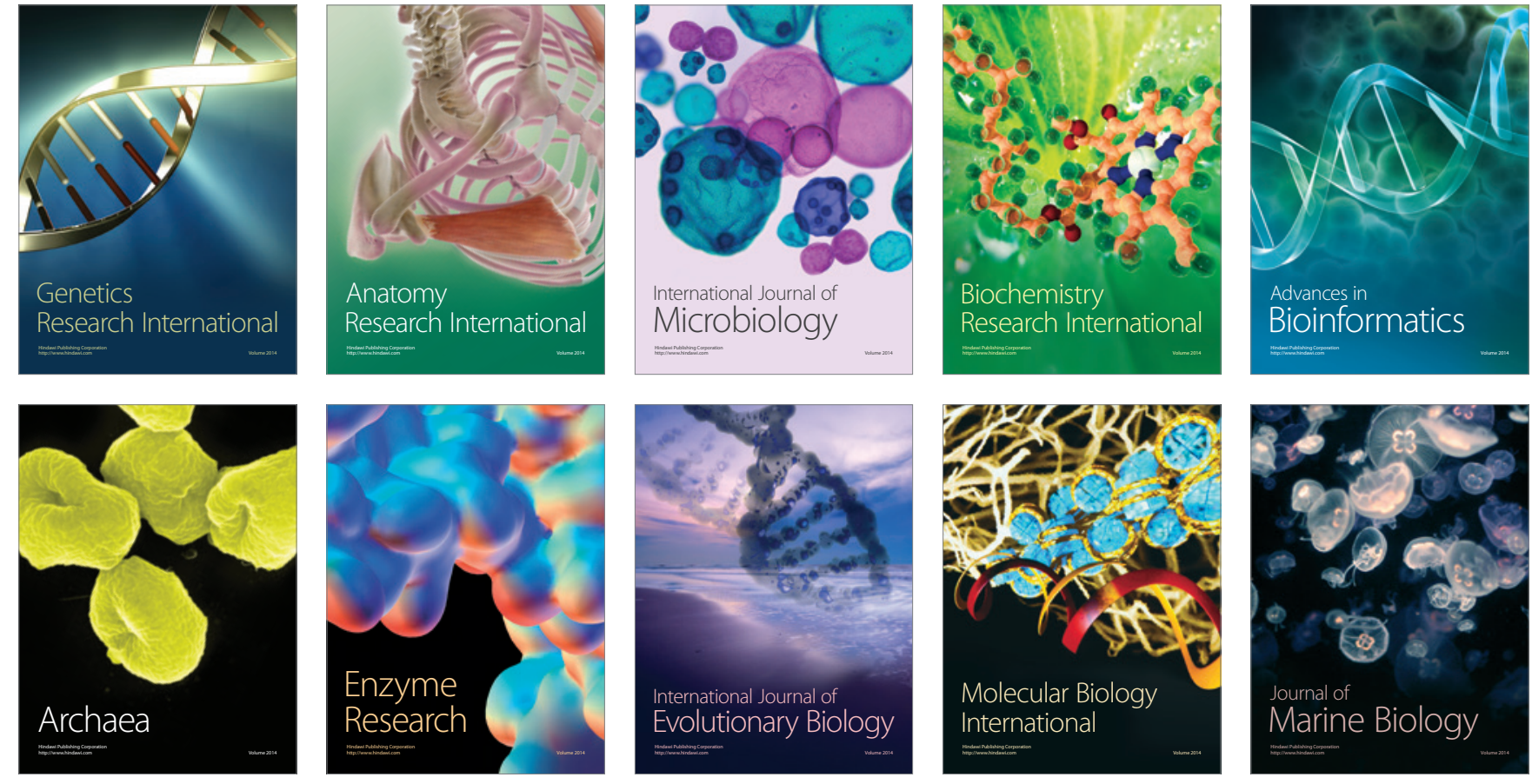